\title{
Materialism is Not the Solution
}

\author{
On Matter, Form, and Mimesis
}

\section{Graham Harman}

\begin{abstract}
A в STR Aст This article defends a new sense of "formalism" in philosophy and the arts, against recent materialist fashion. Form has three key opposite terms: matter, function, and content. First, I respond to Jane Bennett's critique of object-oriented philosophy in favor of a unified matter-energy, showing that Bennett cannot reach the balanced standpoint she claims to obtain. Second, I show that the form/function dualism in architecture gives us two purely relational terms and thus cannot do justice to the topic of form. Third, I argue against Greenberg, Heidegger, and McLuhan that content cannot be trivialized in favor of deeper form. I close with a new conception of mimesis as performance rather than as the fabrication of copies. The form underlying any work's content is provided by the spectator herself as the only real object that does not withdraw from the aesthetic scene.

KEYWORDS Formalism, materialism, mimesis, Jane Bennett, Patrik Schumacher, Clement Greenberg, Martin Heidegger, Marshall McLuhan
\end{abstract}

Object-oriented philosophy is often included on lists of recent materialist philosophies. Let me begin by decisively rejecting the term "materialism," which I view as one of the most damaging philosophical temptations of our time. Nonetheless, the people who call object-oriented philosophy materialism are not fools. There is a reason why they see a close proximity between my approach and that of other nearby authors who sympathize with materialism, whereas no one has ever called object-oriented philosophy "Hegelianism" or "Marxism," for instance. For this reason, I will begin by considering the defense of materialism offered by Jane Bennett. That will take us only partway to the goal, since I want to say something about aesthetics. My rejection of materialism is made in favor of something that might be called "formalism." But formalism already has a long and contested history in literature, architecture, and the visual arts. I will try to show that the kind of formalism I advocate has little to do with the familiar sort. In fact, I will try to show that formalism (in the usual sense of the term) and materialism (in every sense of the term) are two faces of the same error. Lastly, I will try to revive a term that is even older and more discredited in the arts than formalism is: namely, mimesis, or the idea that art is primarily an imitation of the world. My claim here is that art is mimesis, but in the theatrical sense of method acting, rather than the productive sense of fabricating imitations. The artist imitates not by producing copies of external things, but by becoming external things. 


\section{Materialism}

The word "form" has several opposites. We speak of form vs. matter, but also of form vs. content and form vs. function. "Matter" is not as versatile, and almost always appears in opposition to form. Whereas form must have some kind of shape - usually a visible one - matter is that which escapes this shape and resists taking on definite contours. This might happen in one of two different ways. Matter can either be some ultimate term into which all derivative shapes break down, as when we say that all physical things are composed of the elements in chemistry's periodic table. But beyond this, matter can also be that which lies in the depth as absolutely formless, an amorphous reservoir more primordial than any definite thing.

This ambiguity defines the two basic types of pre-Socratic philosophy, as Aristotle already noted in the Metaphysics. All pre-Socratic philosophy can be described as materialism of one of the two sorts just distinguished. Either it tries to identify some privileged physical element from which everything else is built (air, water, air/earth/fire/water combined, or atoms) or it chooses instead to defend a formless apeiron from which all of these elements provisionally emerge. Even today, we find two basic kinds of materialism, both of them deriving from pre-Socratic philosophy. First, there is the materialism beloved by the Marxist and physicalist traditions, in which ultimate material elements are the root of everything and higher-level entities are merely secondary mystifications that partake of the real only insofar as they emerge from the ultimate material substrate. This kind of materialism owes everything to the line of Thales, Anaximenes, Empedocles, and Democritus. It generally has a critical flavor, and thus was preferred by the figures of past and presentday Enlightenment standpoints: even tables, trees, and the brain must be eliminated in favor of the ultimate elements, to say nothing of angels, gods, and folk psychologies.

But second, there is the materialism of the apeiron, for which even the physical entities of science are not deep enough since they already have too much particular structure to deserve being called the bottom layer of the cosmos. This brand of materialism inherits the line of Anaximander and Anaxagoras, usually with a bit of Heraclitean flux-loving thrown into the mix. The cosmos is not inherently made of tiny physical pieces, but is an amorphous or hemimorphous whole from which individual pieces arise only as transient local intensities. The world is pre-individual in character, and is made up primarily of fluxes and flows and becomings. The world is basically a continuum, and all attempts to break it 
into local districts are inherently provisional and relative. This type of materialism is usually not critical in flavor, but tends to be holistic and affirmative. All things are interconnected; emotions and social practices are no less real than the particles which themselves are nothing but a fleeting manifestation of a cosmic whole.

Both standpoints have their merits, but object-oriented philosophy firmly rejects them. Against the two kinds of materialism, object-oriented philosophy insists on the rights of form, as that which has structure at every level of scale, and which cannot be reduced either to a privileged layer of triumphalistic physical being, or to a cosmic holism that treats differences as merely continuous gradients in an uninterrupted, quivering flux. The cat and the table may not be eternal, yet they withstand environmental fluctuation nonetheless, and can gain and lose certain attributes or shift their relations to all other things, while only sometimes being infiltrated or destroyed. The world is made neither of physical ultimates nor of a whole, but of objects, and what most typifies objects is that they always have structure or form. Against Heidegger's veneration for the pre-Socratics, we must say that the task of philosophy begins only when it becomes distinct from the surprisingly similar tasks of physics and of cosmic holism: namely, only when philosophy ends the worship of matter and begins to account for the problem of form. This occurs in distinct ways in Plato and Aristotle, who remain the foundational giants of our discipline and are still the two greatest philosophers of the West.

What is ultimately wrong with the two materialist standpoints, which I often call strategies for "undermining" the object? Their shared defect is their inability to account for true emergence at levels other than the most basic one. Consider a body of water such as Lake Michigan. It may be difficult to specify in geological terms exactly when this lake was formed and when it will have changed so much as to turn into something else completely. But let's suspend that problem for a moment. There is a certain stability to Lake Michigan despite the fact that its population of water molecules is never quite the same. Evaporation occurs constantly. Water splashes ashore with the waves and some of it is lost for good, and the coastline alters slightly. Tourists sometimes pour unwanted drinking water over the side of the boat, augmenting the lake with what used to be the consumer's Evian or Dasani. Some rivers flow directly into the lake. And of course, somewhere it may be raining. While it may never be clear precisely where the lake begins and ends, it is purely arbitrary to claim that the lake is identical with its exact population of water molecules at the moment. The lake has lake-effects not found in individual droplets 
of water, and might have an endless number of other effects that it does not currently have. The lake has a robust character that withstands the arrival or departure of its individual droplets. The lake has a structure different from the structure of other things. In short, the lake is a form. The scientistic lake would treat it nominalistically as just a nickname for a series of varying collections of water that have enough family resemblances over time that we can call it "Lake Michigan" in a loose and only a loose sense. Meanwhile, the holistic position would treat it as just a zone of relative lakeness, one that is basically continuous with neighboring lakes and with the shore. What both materialisms miss is the way in which the lake cuts itself off from its neighbors and its own causal components, allowing a certain degree of entry and exit to all the forces of the non-lake, but remaining a form that endures for some time even if not eternally. The lake endures until other entities actually do the signifcant and not inevitable work of destroying or changing it.

Object-oriented philosophy treats objects as forms that do not automatically dissolve back into that from which they came. By contrast, materialism is a reductionism that falls short of the true task of philosophy: the study of the elusive forms which are never identical either to that of which they are made or the ways in which they are described or known. The form of the object is that which hides midway between its material substrate and its concrete manifestation at any given moment in any given context. Forms are hidden in the floorboards of the world, and cannot be known by replacing them with something that seems to be known already: whether it be their constituent material or their effects. In this sense, materialism is a strictly anti-philosophical position, and that is why I have written elsewhere that materialism must be destroyed. ${ }^{1}$ Many of the calls for "materialism" today are calls to resume the Enlightenment legacy of critique, in the sense of the debunking of superstition and a critique (from the Left) of existing social institutions. But while this tradition has much to be proud of, it is unclear that we can or should extrapolate it into the future, given the intellectual weakness of the materialism whose banner it waves. The work of debunking and of revolution may need to be transformed rather than extended in view of new intellectual circumstances, or else it risks turning into a moralistic revival movement.

We can only expect that this call for a non-materialist philosophy will be attacked by its enemies, who have much to lose if the project succeeds. But what about the intellectual friends and neighbors of object-oriented philosophy, who continue to call for materialism as a way to address object-oriented defects? As promised, I will speak here of Jane Bennett, 
who among other things is an unusually powerful writer. I have written elsewhere about her wonderful book Vibrant Matter. ${ }^{2}$ Here I will deal instead with Bennett's response to me and Timothy Morton in the pages of New Literary History, where Morton and I had proposed different object-oriented theories of literary criticism. ${ }^{3}$ Bennett shows a clear understanding of what object-oriented philosophy is all about, with its attempt to reverse the recent fashion of "networks, negotiations, relations, interactions, and dynamic fluctuations." ${ }^{4}$ When I call it a "prejudice" to favor these terms, Bennett wants me to acknowledge an equal degree of prejudice on my part in favor of objects. And that leads her to proclaim, quite rightly, that a theory ought to be able to deal with both of these extremes. As she puts it:

But perhaps there is no need to choose between objects or their relations. Since everyday, earthly experience routinely identifies some effects as coming from individual objects and some from larger systems (or, better put, from individuations within material configurations and from the complex assemblages in which they participate), why not aim for a theory that toggles between both kinds or magnitudes of "unit"?

Compromise always sounds reasonable. Yet Bennett explains her compromise in terms that quickly return objects to a secondary status. As she has it, the broader compromise position "would then understand 'objects' to be those swirls of matter, energy, and incipience that hold themselves together long enough to vie with the strivings of other objects, including the indeterminate momentum of the throbbing whole." ${ }^{5}$ Notice that far from making a peace offering to object-oriented philosophy, Bennett simply reasserts the privilege of a "throbbing whole" that we already encountered, in germ, in the pre-Socratic apeiron. The main innovation is that Bennett does not just speak of a whole, but also describes it as "throbbing." One online dictionary defines the word "throb," accurately enough, as meaning "to beat or sound with a strong, regular rhythm; [to] pulsate steadily." ${ }^{\prime \prime}$ This word is obviously Bennett's attempt to avoid the specter of stasis that arises whenever we think of the world as a unified whole rather than as carved into discrete and competing districts. That is to say, Bennett wants it both ways. The world is a whole, but also a whole that is somehow injected with a principle of motion and local differentiation. The world needs fluctuation in local intensities in order to avoid a purely motionless apeiron. She also holds that there is a place for objects in this throbbing whole. Objects, we have seen, would be "those swirls of matter, energy, and incipience that hold themselves together long enough 
to vie with the strivings of other objects, including the indeterminate momentum of the throbbing whole." ${ }^{7}$ Bennett's cosmos is a throbbing matter-energy (form is not mentioned) containing local "swirls" that sometimes last long enough to be recognized (by people, it seems) as having a sort of fleeting identity. In order to attain a balanced perspective, we would have "to make both objects and relations the periodic focus of theoretical attention."

This might seem to recall the famous, evenhanded particle/wave duality of light in modern physics. The difference is that if we translate Bennett's views into physical terms, she would treat photons (light particles) as nothing but swirls emerging from a more primordial throbbing wave. In short, she allows for no duality at all, except insofar as people sometimes take swirls to be durable. In echoing the object-oriented dualism between objects and relations, Bennett never explicitly clarifies how relations fit into the picture of the throbbing whole, but given that the word "whole" suggests a pre-established link between all that resides in its embrace, it seems disingenuous for Bennett to suggest that she merely wants a balanced assessment of the two. It is clear enough which term is the dominant one for Bennett and which the dominated. Though adopting the role of a diplomat, Bennett has already shown her anti-object-oriented cards.

Bennett adds that she "finds ... attempts to do justice both to systems and things, to acknowledge the stubborn reality of individuation and the essentially distributive quality of their affectivity or capacity to produce effects, to remain philosophically and (especially) politically productive." ${ }^{8}$ But where is the supposed imbalance in my own approach? She continues:

Harman rejects the very framing of the issue as things-operating-in-systems, in favor of an object-oriented picture in which aloof objects are positioned as the sole locus of all the acting. And yet ... Harman, against that object-prejudice, finds himself theorizing a kind of relation - "communication" - between objects. He tries to insulate this object-to-object encounter from depictions that also locate activity in the relationships themselves or at the systemic level of operation, but I do not think that this parsing attempt succeeds. ${ }^{9}$

With the words "and yet," Bennett suggests that I work at cross-purposes in first insisting on the aloofness of objects and then also, perhaps against my will, referring to a kind of communication between them. But this twofold fate of objects as both communicating and non-communicating is the whole point of object-oriented philosophy, which is designed precisely to create a "balance" between objects and relations that no theory of swirls and throbbing wholes can ever give us. The point 
is not that relations are either non-existent or secondary. The point is that relations are neither automatic nor easy, as the theory of a pre-existent unifying whole would suggest. Humans are not affected by every tiniest thing that happens in their vicinity, just as tectonic plates do not constantly generate major earthquakes and volcanoes do not constantly erupt. Things are not always affected by each other, not always in relation to each other. The claim that all stasis can be reduced to an imperceptible motion simply adopts motion as the principle of the world without earning the right to say so. And despite what Bennett says, objects for me are by no means the sole locus of all the acting, since objects insofar as they are aloof do not act at all: they simply exist, too non-relational to engage in any activity whatsoever. Their relations with other objects are a very special case, and demand an explanation that cannot seriously be provided if we assume that they are always already related in the embrace of a cosmic matter-energy.

\section{Formalism}

I have explained why we must reject materialism, whether it defends one privileged type of entity at the expense of others dismissed as immaterial, or whether it champions a deeper pulsating whole from which all specific entities are held to emerge. Further, I have claimed that both types of materialism are essentially pre-Socratic in origin, and therefore (contra Heidegger) belong to a still immature phase in the history of philosophy when it did not yet struggle with the crucial status of form. Reality consists of objects of all different scales, complicit in the production of other objects, which can never be identified either with the smaller objects that compose them or the larger objects that they compose. Relation and interference occur, but remain somewhat rare. Not everything that happens is relevant to everything else. All things do not reflect all other things as if in a mirror; there are firewalls between things breached only occasionally and with difficulty. What is admirable in materialism is its sense that any visible situation contains a deeper surplus able to subvert or surprise it. Yet this surplus is never shapeless; it always has form. And no level of form can be considered more real than any other. This is why we must defend formalism over materialism: not (as in most formalism) because there is no excess beneath the forms that are given, but because the excess is itself always formed. Here is the problem with Heidegger's view of the artwork as strife between world and earth, since the earth that juts through in Heidegger's artwork has too much of Bennett's throbbing whole about it. ${ }^{10}$ Earth is not formed, but acts only to subvert any given form, just as his Being is too often hinted to be a 
One in opposition to the many beings, rather than being treated as the hidden faces of the many individual beings.

Having defended form against matter, I would now like to defend it against function and content as well. The duel of form and function is most familiar in architecture, where functionalist architecture embeds the art of building in a system of wider social needs, while formalist architecture rejects this task and occupies itself with the self-contained character of visible form. The architect Patrik Schumacher rejects both extremes in the following way:

Architectural discourse is organized around the lead-distinction of form versus function. Architecture, like all design disciplines, hinges upon this distinction. That architecture always has to address both terms of this distinction has been asserted over and over again by many architects and architectural theorists. Whenever one term of the distinction seems to be in danger of being neglected, vehement reminders are issued ... There are countless instances of this theoretical steering effort against the twin evils of a one-sided Formalism and one-sided Functionalism. The perennial Formalism-Functionalism controversy is itself the clearest evidence for the thesis proposed here that the distinction between form and function is the lead-distinction of architecture/design and thus a fundamental, permanent communication structure of [architecture]. ${ }^{11}$

While Schumacher, like Bennett, strives to balance two concerns, there is a sense in which form and function are not distinct at all. Note that functional concerns treat architecture in its relation to external needs, such as the features of housing or schooling or government that a building must serve, so that the building is dissolved into ulterior purposes. But note as well that even form is relational, since it is always a form for designers and observers. Form in Schumacher's sense is still not the building itself, but merely its outward look. Whether we consider the building as existing for a client with practical needs, or for an avant-garde architectural public, in both cases the building is overdetermined by its relations. The building itself remains unacknowledged as a source of surprise or resistance to both its formal and functional concerns.

This is reminiscent of the usual reading of Heidegger's famous toolanalysis. ${ }^{12}$ As is well known, Heidegger distinguishes between the present-at-hand and the ready-to-hand. To perceive an object is to perceive its form or outward look (Schumacher's "formal"); to use an object is to let it function in relation to all other objects in a referential whole (Schumacher's "functional"). The hammer has a definite visual look, yet this look emerges only rarely in cases of breakdown; the rest of the time, 
the hammer functions smoothly in relation to a whole system of other things. This often yields the interpretation that Heidegger shows us that praxis comes before theory, or (in architectural terms that he never uses) function before form. Heidegger argues further that the visible hammer seems to be independent, while the functional hammer belongs to a systematic whole. Yet as I have often argued, this cannot be the case. The hammer's true independence comes not from the fact that it is sometimes seen as an isolated thing, but from the fact that it can break. And insofar as the hammer can break, this makes it a surplus not contained in the holism of systematic functions anymore than the kingdom of visible form. Insofar as we see the hammer, it exists in relation to us; insofar as the hammer is engaged in relation with nails, boards, and construction projects, it exists in relation to these other things. But the fact that the hammer can break shows that it is deeply non-relational, that it resists being appropriated by us and by other equipment. What is this real hammer lying in the depths, beneath our perceptions and beneath all invisible function? This real hammer is also a form, since it has structure and qualities that distinguish it from all other things, but a form that exists regardless of any contact with us or anything else. It is not unlike what the medievals and Leibniz called "substantial form." This deeper formalism of objects simultaneously refutes materialism, functionalism, and formalism (in the derivative sense of outward visual look).

Let's speak now of the opposition between form and content. This will prove to be the most important of the three, since form and content turn out to be a more ambiguous pair than the others. And here we will make use of the great Canadian media theorist Marshall McLuhan, perhaps the most explicit champion of form against content. When McLuhan speaks of media, he is speaking of the hidden background condition of any medium that makes its content irrelevant. ${ }^{13}$ It is foolish to speak of the difference between good and bad radio shows, since what is really at stake are the features of radio itself: which differ from those of newspapers or television, and which structure our consciousness differently regardless of how we judge the content of individual programs. The content of any medium, McLuhan once provocatively remarked, is no more relevant than the graffiti on an atomic bomb. ${ }^{14}$ The medium itself is the deep, the unnoticed, and the decisive. Gutenberg's press is of greater significance in changing ratios of human perception than any Bible or other book that came from it. ${ }^{15}$ Like Francis Bacon (one of his heroes) McLuhan thinks that objects are not what their surface properties tell us, since in Bacon's words "every body contains in itself many forms of natures united together in a concrete state, 
[and] the result is that they severally crush, depress, break, and enthrall one another, and thus the individual forms are obscured."16

It seems at first that for McLuhan, depth is everything and surface is a mere distraction. In this respect he obviously resembles Heidegger, whose contempt for the surface of beings is no less vivid than McLuhan's own. For Heidegger, any surface configuration of the world is merely "ontic," whereas the real is that which is veiled, concealed, sheltered, harbored, or withdrawn. But along with McLuhan and Heidegger, we should add a third dark knight of depth against surface: Clement Greenberg. ${ }^{17}$ At first it might sound counterintuitive to call Greenberg a theorist of depth. After all, it was he who defended the flatness of painting and denounced the post-Renaissance tradition of three-dimensional illusionism as a spent force, as the very embodiment of "academic art" in his time. Yet the point is not so much that the flat canvas is flat, but the fact that it is a medium deeper than any possible content. For Greenberg, pictorial content degenerates into "literary anecdote" unless it somehow incorporates a reference to the flatness of the painting. Consider his rejection of Salvador Dali as just another academic painter, since for all the bizarreness of his content he uses the same now-discredited techniques of postRenaissance illusionism that we find in full-blown academic painting. ${ }^{18}$ Or even more surprisingly, consider his rejection of Kandinsky, who in Greenberg's view misunderstands the essence of cubism as abstraction rather than as flatness, and thus gives us circles and triangles floating in empty space in a way that indulges in what Greenberg calls "academic reminiscence," or even "provincialism." ${ }^{19}$ For Greenberg the canvas medium is the depth hiding behind any surface content, which is obliged to incorporate that depth in some way for any painting that wishes to be avant-garde rather than academic.

Yet all intellectual theories of depth have the inherent problem that there is not much for us to say about a depth beneath all access. Some such theories, including Heidegger's, have the additional problem that we cannot gain access to this minimal depth in the first place. By belittling content at the expense of form, Heidegger, McLuhan, and Greenberg seem to give little role to content other than to be mocked by its deeper condition. Nonetheless, all three of these authors are aware of this problem to some extent, and all are forced to give way to what we might call "the revenge of the surface." Heidegger, after all, is less a theorist of being than of human Dasein's striving towards this being. Being needs us, he says, in order to come to presence in manifold ways through the unfolding of the history of being. Perhaps more importantly, though Hei- 
degger did not quite see this, his theory of the withdrawal of all beings makes causal relation itself into a problem. If we push his theory of tools beyond its initial holism, we are not only led to a hammer-in-itself and nail-in-itself outside the tool-system. We also need to ask how a hammer could ever hit a nail in the first place if they are both too deep to engage in mutual contact. If tool-beings exist only at an ultimate depth for Heidegger, then their relations can only occur on the most superficial surface of the world. Whereas Gilles Deleuze tends to view surfaces as loci of sterile effects, for Heidegger there is the paradoxical fact that events must unfold entirely on the surface.

In Greenberg's case, it cannot just be a question of an artist's reflexive awareness that there is a flat canvas medium behind the content of a painting. This insight is quickly mastered, but not all masterpieces of modern painting do it in precisely the same way. Displaying a plain white canvas is not the best artwork imaginable, since even for Greenberg the aesthetic challenge of such a work would not be very rich. What is crucial for Greenberg is the way the content of the painting assimilates background flatness and embeds it within the content, which thereby rises above the literary anecdote of academic painting that takes an illusionistic three-dimensional tradition for granted. There are still at least two problems here - and they are historical problems, despite Greenberg's admission that flatness is binding only for a limited era of art. The first points backward in time. Since Greenberg concedes that incorporation of the flat background is the principle of advanced art only in his own time, by what criteria shall we judge pre-modern painting? It is noteworthy that while Greenberg occasionally passes judgments on the older Florentines and Venetians and Spaniards, these topics occupy a relatively minimal part of his output, and often seem free-floating or unconnected with his general theory of painting. Do Raphaël or Velasquez exceed their lesser contemporaries through better incorporation of the conditions of the background medium, or is it not for some other reason? The second problem points forward in time. Doesn't the principle of hinting internally at the background medium eventually grow as stale as every other principle? Is it not the case that abstraction itself turned into academicism, despite Greenberg's definition of academic art as "art that is unaware of its medium"? Unless we wish to read the history of art after Pollock, Noland, and Olitski as a prolonged decadence with no end in sight, art needs a different guiding principle than flatness. Artists themselves have known this for half a century.

In the case of McLuhan, the revenge of the surface is even more ob- 
trusive. For all his talk of the inaccessibility of the background medium, these media do nothing but silently dominate us. Their very depth makes them unable to communicate with us or with each other, just like Heidegger's tool-beings. The only two ways in which McLuhan allows media to change are both surface-events. The first is what he calls the reversal of the overheated medium, when the quantitative increase or overdevelopment of a given medium overloads the world with information, leading to a sudden flip of the medium into something that looks like the opposite. Cars begin as a speedy convenience and tool of freedom, but eventually turn into urban clutter: increasing our travel time, the pollution of our breath, and slavery to parking ramps, banks, and insurance companies. Note that all these effects are side-effects, emanating not from the inherent functional shape of the car itself, but from its accidental surface features such as price, exhaust, and metallic bulk. The second way media change is through what McLuhan calls retrieval. We are surrounded with the dead media of yesteryear, but McLuhan grants artists the special power to revive these dead clichés by bringing them into relation with the living background of our own time, thus making the dead things credible again. In this sense artists are "the antennae of our race," not because they glimpse the hidden background of the world in superhuman fashion, but because they turn the dead forms of the past into creatures of the background.

But not only does the formerly despised surface become our fresh gateway into the dark and rumbling underworld. More than this, we discover that the depth is not something distinct from the things, but is incarnated directly in them. Think again of Heidegger's "earth," which supposedly juts forth in every artwork. The problem is that earth tends to be just as monistic as his concept of Being. Just as Being is always the same no matter in what plurality of beings it chooses to manifest itself, earth is the same earth in every artwork. Or maybe not, you say? Maybe Heidegger realizes that the earthy red of a painting is different from the earthy gold leaf of another, just as it differs from the earthy marble of a sculpture? But in that case he has already conceded the central point: that the earth is many rather than one, and that the depths are already formed.

Think too of Marshall McLuhan. Unless we accept that only media revolutions show any skill, and thus that all radio and television programs are equally stupid in their ignorance of the background, we have to conclude that McLuhan allows for more and less successful programs, with the more successful ones shaping their content in a way that better reflects the inherent conditions of the medium. McLuhan seems to 
know this, since he reports that Kennedy defeated Nixon in their debate among television viewers, while those listening on radio tended to favor Nixon - a sign that Kennedy-content was a better match for one medium and Nixon-content for another. ${ }^{20}$ Or consider McLuhan's related assertion that Hitler could never have risen to power in the age of television, a medium in which his shrill proclamations would have been ridiculous to the masses rather than energizing. Greenberg must make the same concession. The background incorporated by all the aspects of a modern painting cannot just be a single canvas apeiron like that of the pre-Socratics, since then the flat canvas would jut forth in the same way in each image. All elements of all paintings would be interchangeable stand-ins for each other, as long as each performed the sole task of hinting knowingly at the background behind them. Instead, each painting, each artwork, must generate its own background. More than this, each part of each artwork must have its own background, so that we do not fall into the untenable holism of claiming that an artwork is a well-oiled machine in which each part is thoroughly determined by all the rest. If this were the case then any modification of any artwork, however trivial, would result in the production of a completely new artwork. It would be art as a "bundle of qualities," to use David Hume's famous and regrettable phrase.

In short, the relation between figure and ground cannot be the relation between many and one. Each figure embodies its own ground, and embodies it concretely. In the terms of ancient philosophy, this is analogous to a shift from Plato to Aristotle. One of the clearest but least convincing aspects of Alain Badiou's Logics of Worlds is his basically Platonic conception of art. ${ }^{21}$ Art, of course, is one of Badiou's four "truth procedures," which he tells us have been the same four since at least Ancient Greece. The others are politics, love, and science, (though science is inexplicably replaced in Logics of Worlds by the easier case of mathematics). Badiou is concerned to secure the objectivity or even eternity of these truth procedures. Romantic love, especially of the heterosexual sort, is freed from all historicizing and is described as a recurrently enacted truth. Politics is guided at all points in history by the "communist invariant." Mathematics, the easiest case of the four, bears witness to truths about prime numbers that weigh heavily on every subject, irrespective of historical time or place. This leads him to a rather unconvincing account of art, one that Greenberg would have dismissed as a reversion to academicism. Badiou's example of an artistic invariant is that both Picasso and prehistoric cave painters painted horses, and that the same "horsiness" is at work in both cases. There is an invariant form of the horse across 
thousands of years. Although Badiou seemingly allows art to deal with a plurality of backgrounds (since there are many other things one might paint besides horses), to say that both cave painters and Picasso are painting the same thing is a needlessly literal reading of both, and mainly serves a Platonizing function of creating a forced analogy between art and mathematics, the love of Badiou's life. It would be closer to true if we said that pre-historic art gives us one horse and Picasso gives us another. Each painted horse is a different horse, just as for Aristotle there is no perfect eternal horse-form, but simply many individual horses. But what is the individual aesthetic horse behind the pigments through it which it is suggested? Or more generally, what is the relation between the form and the content of any given thing?

\section{Mimesis}

One of the central concepts of object-oriented philosophy is the notion of objects as withdrawn from access, so that only their sensual qualities are accessible. This already gives us something that Heidegger's position cannot, since it zeroes in on Being as plural rather than as a hemimorphous apeiron, as in Heidegger's works. This already oversimplifies a broader situation, since the tension between concealed objects and their tangible qualities is just one instance of tension between objects and their qualities. Under the object-oriented model, there are actually two kinds of objects (the real and the sensual) and two kinds of qualities (the real and the sensual again). ${ }^{22}$ Each type of object is bonded to each type of quality, yielding a fourfold of real objects, real qualities, sensual objects, and sensual qualities, with time, space, essence, and eidos as the four possible permutations in the group. I mention this only to indicate the scope of the problem, since only one of the four is relevant to us here: the tension between real objects and sensual qualities, which can be identified with space, and whose breakdown can be called allure. ${ }^{23}$

The theory goes as follows. Whereas in everyday perception we tend to identify a tree or an apple with its series of manifest qualities, there are special cases in which the tree, apple, or anything else suddenly seems to stand at a distance from these qualities. Metaphor is a good example. If we say "Churchill is like Roosevelt," there is no metaphorical effect, since the two compared items have such an obvious historical similarity that the resemblance creates no friction. But if we follow Ortega's example and say "a cypress is like a flame," this metaphor (in the special case of a simile) does not have a banal effect unless we are inattentive, or unless we have read the poem many times before and have now lost interest. ${ }^{24}$ 
Though cypress and flame do have a vaguely similar shape, this similarity seems so accidental that their marriage seems far less possible than that of Churchill and Roosevelt. What happens, according to Ortega's analysis, is that the palpable flame-qualities seem to cluster around the cypress as the tree's own properties. Yet it is not the easily accessible cypress of perception, since this tree already has banal qualities of its own. Instead, the cypress in the metaphor is like the hammer following its Heideggerian breakdown: our attention is drawn to it, yet it is still a withdrawn enigma inaccessible to us, incommensurable with any possible relation we might have to it.

The problem arises as to how, if this cypress is withdrawn, it could ever participate in the metaphor. Is the metaphor nothing but a set of accessible flame-qualities supplemented by the cypress tree as an absent void? In a sense yes, but this is only one side of the situation. The flamequalities cannot be attached to the sensual cypress that we see and talk about, because then it would simply be a failed comparison: we know that the cypress tree shares few if any important qualities with flames. But qualities never exist without an object, and if these flame-qualities cannot belong to any object of sense, then they can only belong to a real object. Yet we have seen that the real cypress (like all others) is inherently withdrawn, which means that it cannot touch anything else: not even poetic flame-qualities. And this seems to leave us at a dead end.

But there is one alternative, which I mention with reluctance since it took me years to begin to accept. When speaking of cypress and flame, the real objects to which these words refer are both withdrawn, stationed beyond all possible direct access, including even access of the causal kind. Only one real object is present on the scene, fully involved in the situation rather than withdrawn: and that object is each of us, as readers of the poem (or the author, who is also a reader). Since we cannot hope to bind sensual flame-qualities to an absent real cypress, we must concede the strange result that each of us is the real object to which the flamequalities become attached. Stated differently, each of us as readers (if we are not bored or unmoved or distracted) becomes the cypress tree, just as method actors are supposed to become the tree or rock they are assigned to portray.

This is the surprising sense in which we must defend the long-abandoned concept of mimesis: not that art is about producing imitation things that copy natural things, but that it imitates in the sense that actors imitate rocks, trees, Jim Morrison, or Nixon. The role of being a tree is transferred from the tree to us, with the difference that we ourselves are 
now trees with flame-qualities, which orbit us impossibly like demonic moons. This model would shed light on Aristotle's interesting remark that the poet must be nearly insane, crying when writing a tragedy and enraged when presenting the wrath of Achilles. In this way, it seems that the form of any aesthetic content must be found in the involvement of the spectator of that content. One implication of this has already been in the air for awhile: an end to irony, self-reflexivity, distance, and the placing of everything in quotation marks. Just as the notion of critique as tearing things down with a sneer from nowhere should be replaced by the critique of wine and food critics and their deep personal investment in their topics, sincerity may need to return to places in art from where it has long been exiled. Oscar Wilde once remarked that "all bad poetry is sincere," and perhaps he would have extended this remark to the arts in general. And though the critic Harold Bloom claims that Oscar Wilde is right about everything, it is a small step from being right about everything to being wrong about everything. What if Wilde's remark were valuable precisely because it finds the truth precisely in negating it? What if it were the case that all good art is sincere, in the sense that it provokes our investment precisely by placing us inside the scene, letting us step in as understudies for the real object, forcing us to play the part of the cypress enslaving the qualities of the flame? If this were the case, then all art would be a branch of the performing arts. Form defeats content, not because content must refer to its background medium, but because aesthetic participants themselves provide that medium, standing in for the cypress and stone that cannot attend in person.

\section{Notes}

1. Graham Harman, "I Am Also of the Opinion That Materialism Must Be Destroyed," Society and Space 28, no. 5 (2010): 772-90. See also Graham Harman, "Realism Without Materialism," SubStance 40, no. 2 (2011): 52-72.

2. Jane Bennett, Vibrant Matter: A Political Ecology of Things (Durham, NC: Duke University Press, 2010.) For my review of this book see Graham Harman, "Autonomous Objects," new formations, no. 71 (2011): 125-30.

3. Jane Bennett, "Systems and Things: A Response to Graham Harman and Timothy Morton," New Literary History 43, no. 2 (Spring 2012): 225-33. This is a response to Graham Harman, "The Well-Wrought Broken Hammer: Object-Oriented Literary Criticism," New Literary History 43, no. 2 (Spring 2012): 183-203, and Timothy Morton, "An Object-Oriented Defense of Poetry," New Literary History 43, no. 2 (Spring 2012): 205-24. 
4. Bennett, "Systems and Things," 226, citing from Harman, "The WellWrought Broken Hammer," 187.

5. Bennett, "Systems and Things," 227.

6. Oxford Dictionaries, http://oxforddictionaries.com/definition/english/throb.

7. Bennett, "Systems and Things," 227.

8. Bennett, "Systems and Things," 228.

9. Bennett, "Systems and Things," 228.

10. Martin Heidegger, "The Origin of the Work of Art," in Off the Beaten Track, trans. J. Young \& K. Haynes (Cambridge: Cambridge University Press, 2002.)

11. Patrik Schumacher, The Autopoiesis of Architecture, vol. 1 (London: John Wiley \& Sons, 2011), 207.

12. For a full account of Heidegger's tool-analysis, see Graham Harman, ToolBeing: Heidegger and the Metaphysics of Objects (Chicago: Open Court, 2002).

13. Marshall McLuhan, Understanding Media: The Extensions of Man (Cambridge, MA: MIT Press, 1994); Marshall and Eric McLuhan, Laws of Media: The New Science (Toronto: University of Toronto Press, 1992).

14. Marshall McLuhan, "The Playboy Interview: Marshall McLuhan," Playboy, March 1969.

15. Marshall McLuhan, The Gutenberg Galaxy (Toronto: University of Toronto Press, 2011).

16. Francis Bacon, The New Organon, Book 2, 24. Edited by F. H. Anderson (Indianapolis: The Library of Liberal Arts, 1960).

17. See Graham Harman, "The Revenge of the Surface: Heidegger, McLuhan, Greenberg," Paletten 291/292 (2013): 66-73. English translation by the author of the German booklet: Graham Harman, Die Rache der Oberfläche: Heidegger, McLuhan, Greenberg (Köln: Verlag der Buchhandlung Walther König, forthcoming 2013).

18. Clement Greenberg, The Collected Essays and Criticism, vol. 1, Perceptions and Judgments, 1939-1944 (Chicago: University of Chicago Press, 1986), 9, note 2.

19. Clement Greenberg, The Collected Essays and Criticism, vol. 2, Arrogant Purpose, 1945-1949 (Chicago: University of Chicago Press, 1986), 3-4.

20. McLuhan, Understanding Media, 329.

21. Alain Badiou, Logics of Worlds, trans. A. Toscano (London: Continuum, 2009.)

22. See Graham Harman, The Quadruple Object (Winchester, UK: Zero Books, 2011).

23. For a discussion of allure, see Graham Harman, Guerrilla Metaphysics: Phenomenology and the Carpentry of Things (Chicago: Open Court, 2005).

24. José Ortega y Gasset, "An Essay in Esthetics by Way of a Preface," Chapter 8 of Phenomenology and Art, trans. P. Silver (New York: Norton, 1975). 